Supplement of Earth Surf. Dynam., 6, 989-1010, 2018

https://doi.org/10.5194/esurf-6-989-2018-supplement

(C) Author(s) 2018. This work is distributed under

the Creative Commons Attribution 4.0 License.

(c) (1)

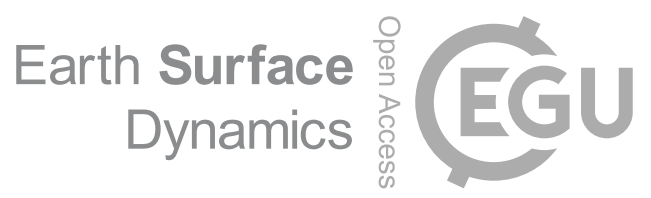

Supplement of

\title{
Morphodynamic model of the lower Yellow River: flux or entrainment form for sediment mass conservation?
}

\section{Chenge An et al.}

Correspondence to: Chenge An (anchenge08@163.com) and Xudong Fu (xdfu@tsinghua.edu.cn)

The copyright of individual parts of the supplement might differ from the CC BY 4.0 License. 

In this paper, we implement the relation of Dietrich (1982) to calculate sediment fall velocity $v_{s}$. The relation is,

$3 \quad v_{s}=R_{f} \sqrt{R g D}$

$4 \ln \left(R_{f}\right)=-b_{1}+b_{2} \ln \left(\operatorname{Re}_{p}\right)-b_{3}\left[\ln \left(\operatorname{Re}_{p}\right)\right]^{2}-b_{4}\left[\ln \left(\operatorname{Re}_{p}\right)\right]^{3}+b_{5}\left[\ln \left(\operatorname{Re}_{p}\right)\right]^{4}$

$5 \quad \operatorname{Re}_{p}=\frac{\sqrt{\operatorname{Rg} D} D}{v}$

$$
v_{s}=\frac{R g D^{2}}{C_{1} v+\left(0.75 C_{2} \operatorname{Rg} D^{3}\right)^{0.5}}
$$

Another widely used relation for sediment fall velocity is the relation of Ferguson and Church (2004), which is regarded as applying to nearly the entire range of viscous to turbulent conditions.

where $b_{1}=2.891394, b_{2}=0.95296, b_{3}=0.056835, b_{4}=0.002892, b_{5}=0.000245$, and $v=10^{-6}$ is the kinematic viscosity of water.

where $C_{1}=18$ and $C_{2}=0.4$ for smooth spheres; $C_{1}=18$ and $C_{2}=1.0$ for sieve diameters of natural sand; and $C_{1}=20$ and $C_{2}$ $=1.1$ for nominal diameters of natural sand. More specifically, the relation of Ferguson and Church (2004) converges to Stokes' law for small grains, and to a constant drag coefficient for large grains.

Considering the fact that the sediment of LYR is finer than most sand-bed rivers (Ma et al., 2017), here we compare the two relations for sediment fall velocity in the context of the LYR. The two parameters in Ferguson and Church are specified as $C_{1}=18$ and $C_{2}=1.0$. In our simulation, the sediment size range of the LYR is specified as $15 \mu \mathrm{m} \sim 500 \mu \mathrm{m}$.

According to Fig. S1, the relation of Dietrich (1982) and the relation of Ferguson and Church (2004) coincide with each other within this size range, thus justifying our implementation of Dietrich (1982) in the simulation. For grain sizes smaller than $15 \mu \mathrm{m}$, sediment becomes washload in the LYR and Dietrich (1982) predicts sediment fall velocities that are smaller than those predicted by Ferguson and Church (2004). For sediment coarser than $500 \mu \mathrm{m}$, Dietrich (1982) somewhat overestimates sediment fall velocity compared with Ferguson and Church (2004). 


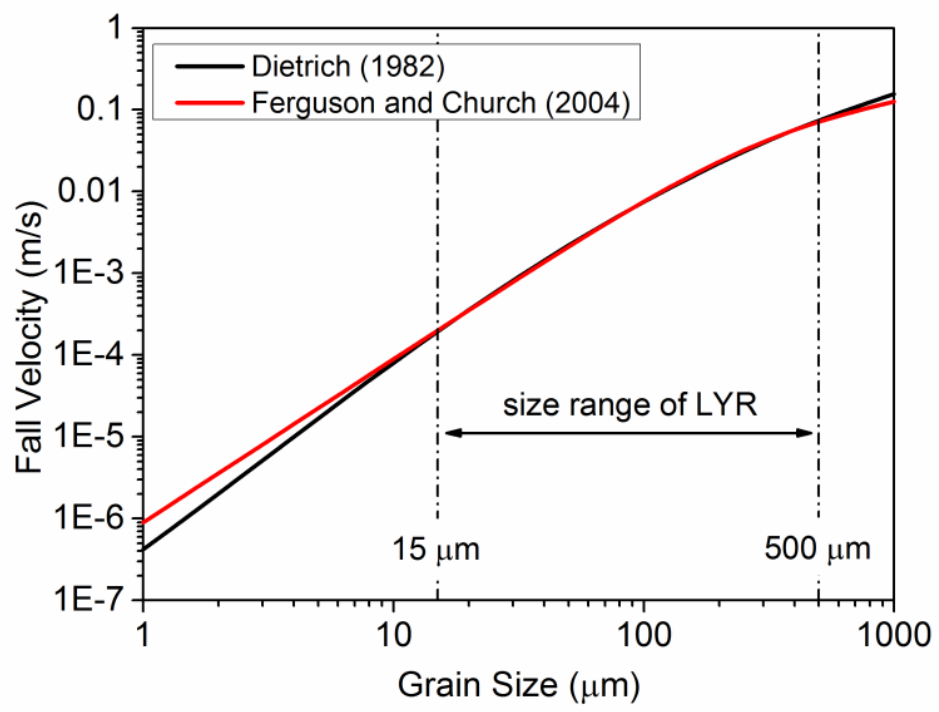

Figure S1. Comparison of two relations for sediment fall velocity: Dietrich (1982) and Ferguson and Church (2004)

\section{S2: Numerical simulation of uniform sediment under hydrographs}

In this section, we conduct additional cases for the case of uniform sediment. The computational conditions are the same as those implemented in Section 3.1 of the main text, except that the unsteady inflow discharge is considered. The flood has a symmetrical triangular hydrograph with a peak discharge of $3000 \mathrm{~m}^{3} / \mathrm{s}$ (corresponding to a discharge per unit width of

$2810 \mathrm{~m}^{2} / \mathrm{s}$ ), a minimum discharge of $300 \mathrm{~m}^{3} / \mathrm{s}$ (corresponding to a discharge per unit width $\mathrm{of}^{2} 1 \mathrm{~m}^{2} / \mathrm{s}$ ), and a flood duration of 4

29 days. Figure S2 shows the hydrograph as used here. The flood intermittency factor is specified as unity since hydrographs are

30 being considered. The sediment supply rate is the same as that in Section 3.1 of the main text, thus corresponding to a cutoff 31 of sediment supply. The hydrograph is repeated for 3 times. 


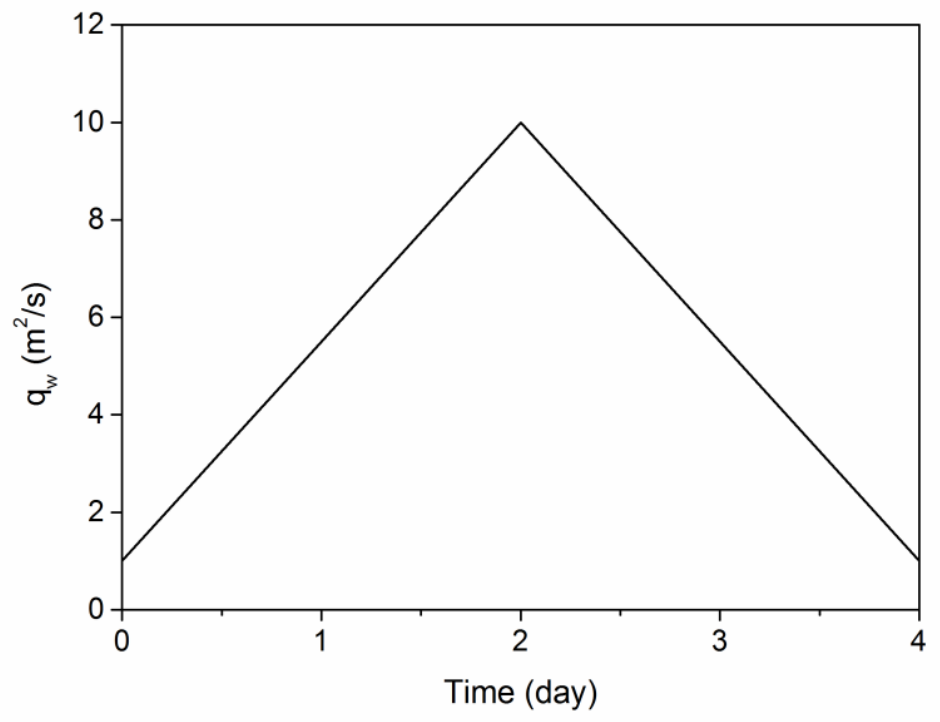

32

Figure S2. Hydrograph of the inflow discharge

Figure S3 shows the river evolution within the 3 floods predicted by the flux form of Exner equation. Due to the 35 cutoff of sediment supply, the bed degrades and the sediment load declines from the upstream end. Moreover, sediment load shows a reduction in the downstream direction at the peak discharge, but an increase at the low discharge, which corresponds to the nonuniformity of the flow hydraulics (i.e. the propagation of a flood wave). Figure S4 shows the river evolution predicted by the entrainment form of the Exner equation, with the sediment fall velocity calculated by the relation of Dietrich (1982). A comparison of Figs. S3 and S4 indicates that the two formulations predict very similar results even when hydrographs are considered. 

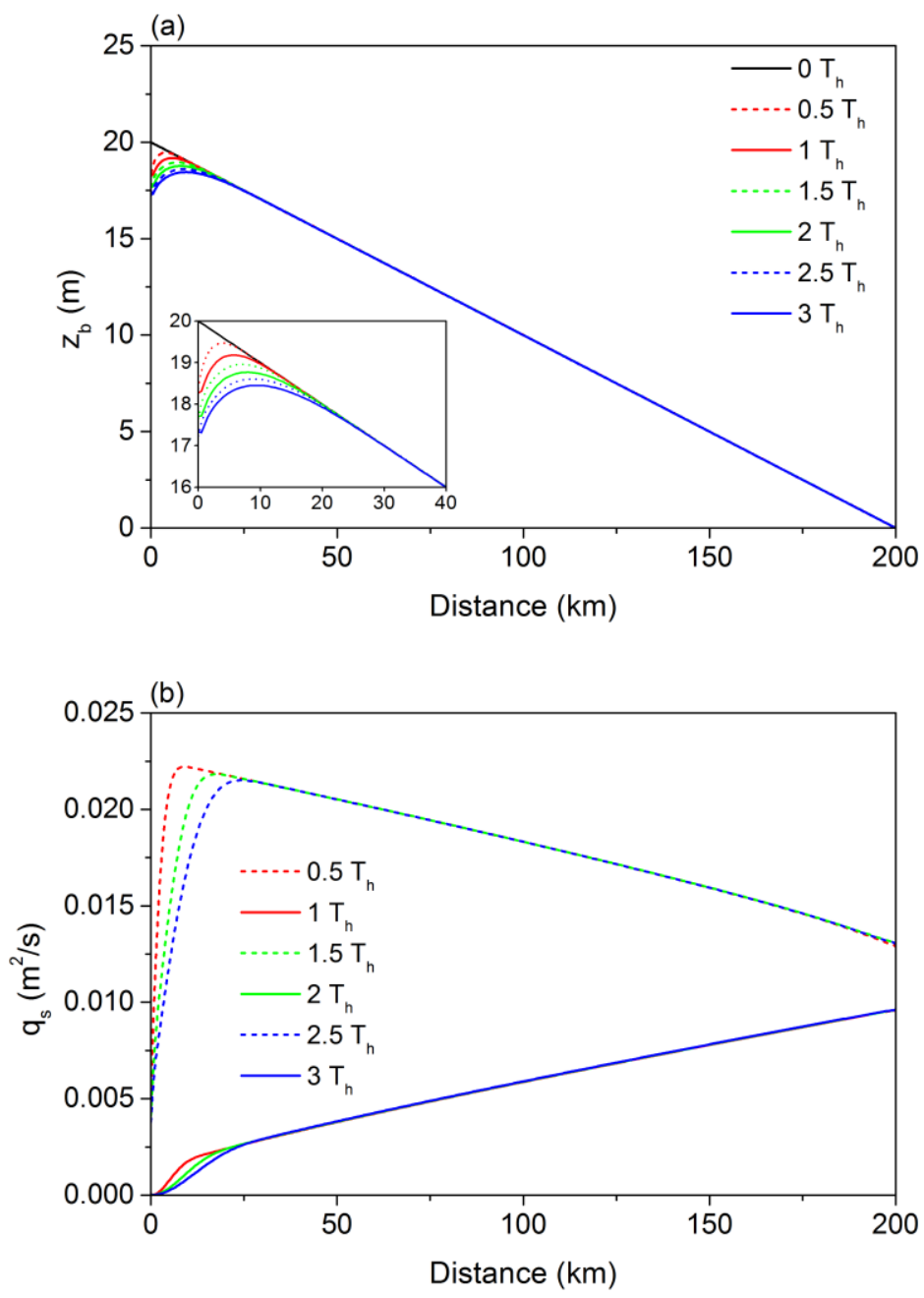

41

42 Figure S3. Results for uniform sediment within 3 hydrographs simulated by the flux form of Exner equation: time variation 43 of (a) bed elevation $z b$, (b) sediment load per unit width $q_{s}$ of the LYR in response to the cutoff of sediment supply. The inset 44 shows detailed results near the upstream end. The dash lines are at the peak discharge and the solid lines are at the minimum 45 discharge. 

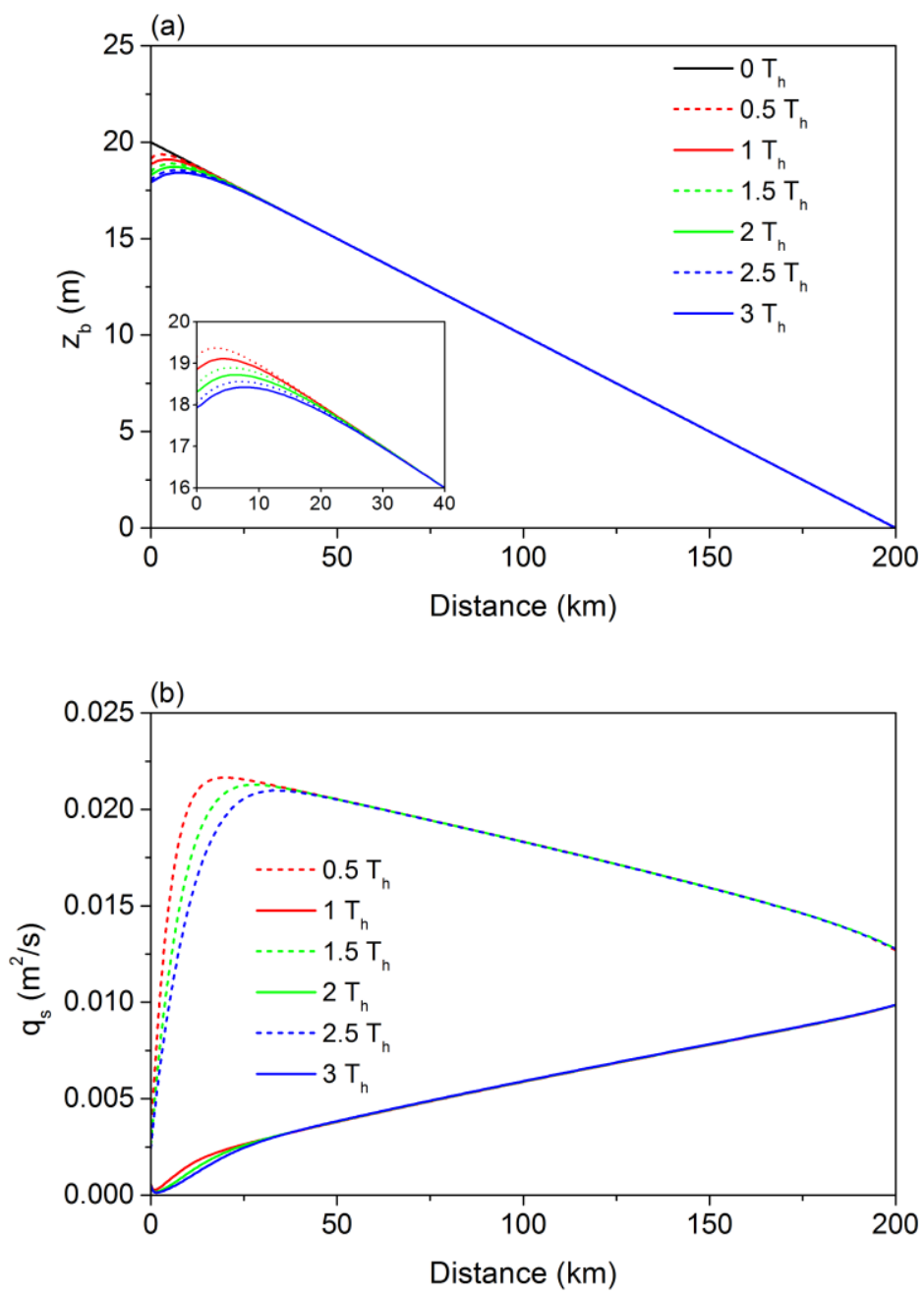

47 Figure S4. Results for uniform sediment within 3 hydrographs simulated by the entrainment form of Exner equation: time 48 variation of (a) bed elevation $z b$, (b) sediment load per unit width $q_{s}$ of the LYR in response to the cutoff of sediment supply. 49 The inset shows detailed results near the upstream end. The dash lines are at the peak discharge and the solid lines are at the 50 minimum discharge.

\section{$51 \quad$ S3: Numerical simulation of sediment mixtures under hydrographs} same as those implemented in Section 3.2 of the main text, except that the unsteady inflow discharge is considered. The flood 
hydrograph is identical to that in Section S2, as shown in Fig. S2. The sediment supply rate is the same as that in Section 3.2 of the main text, thus corresponding to a cutoff of sediment supply. The hydrograph is repeated for 3 times.

Figure S5 shows the river evolution within the first 3 floods predicted by the flux form of Exner equation, and Fig. S6 shows the river evolution predicted by the entrainment form of Exner equation. The sediment fall velocity is calculated by the relation of Dietrich (1982). Even though the river morphodynamic processes become much more complicated when the hydrograph rather than constant flow discharge is considered, a comparison of Figs. S5 and S6 still shows that the two formulations predict very different patterns of grain sorting. Kinematic waves are evident in the flux form, but no kinematic waves are evident in the entrainment form.
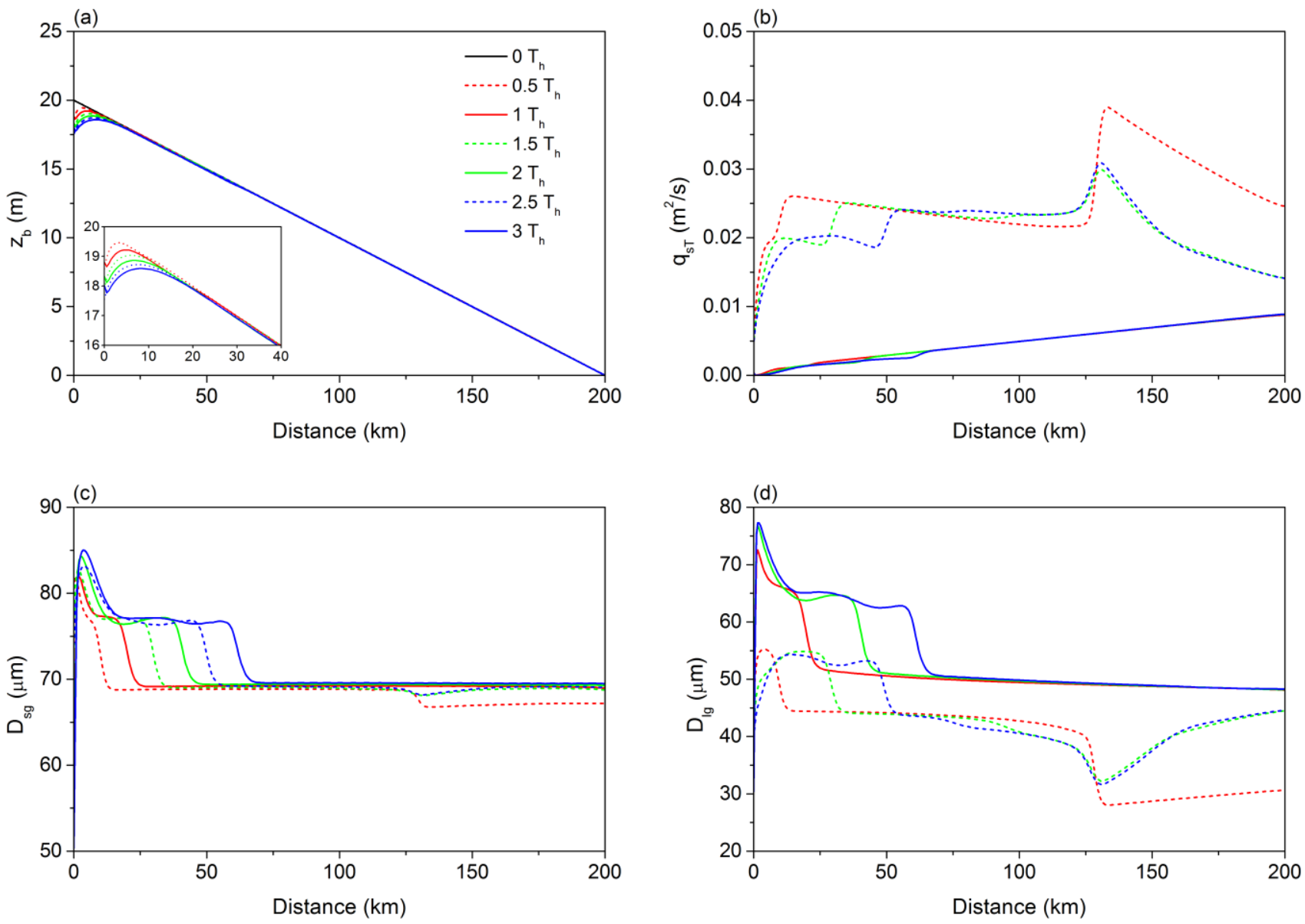

63

64 Figure S5. Results for sediment mixtures within 3 hydrographs simulated by the flux form of Exner equation: time variation 65 of (a) bed elevation $z_{b}$, (b) total sediment load $q_{s T}$, (c) surface geometric mean grain size $D_{s g}$ and (d) geometric mean grain size 
66 of sediment load of the LYR in response to the cutoff of sediment supply. The inset shows detailed results near the upstream end. The dash lines are at the peak discharge and the solid lines are at the minimum discharge.
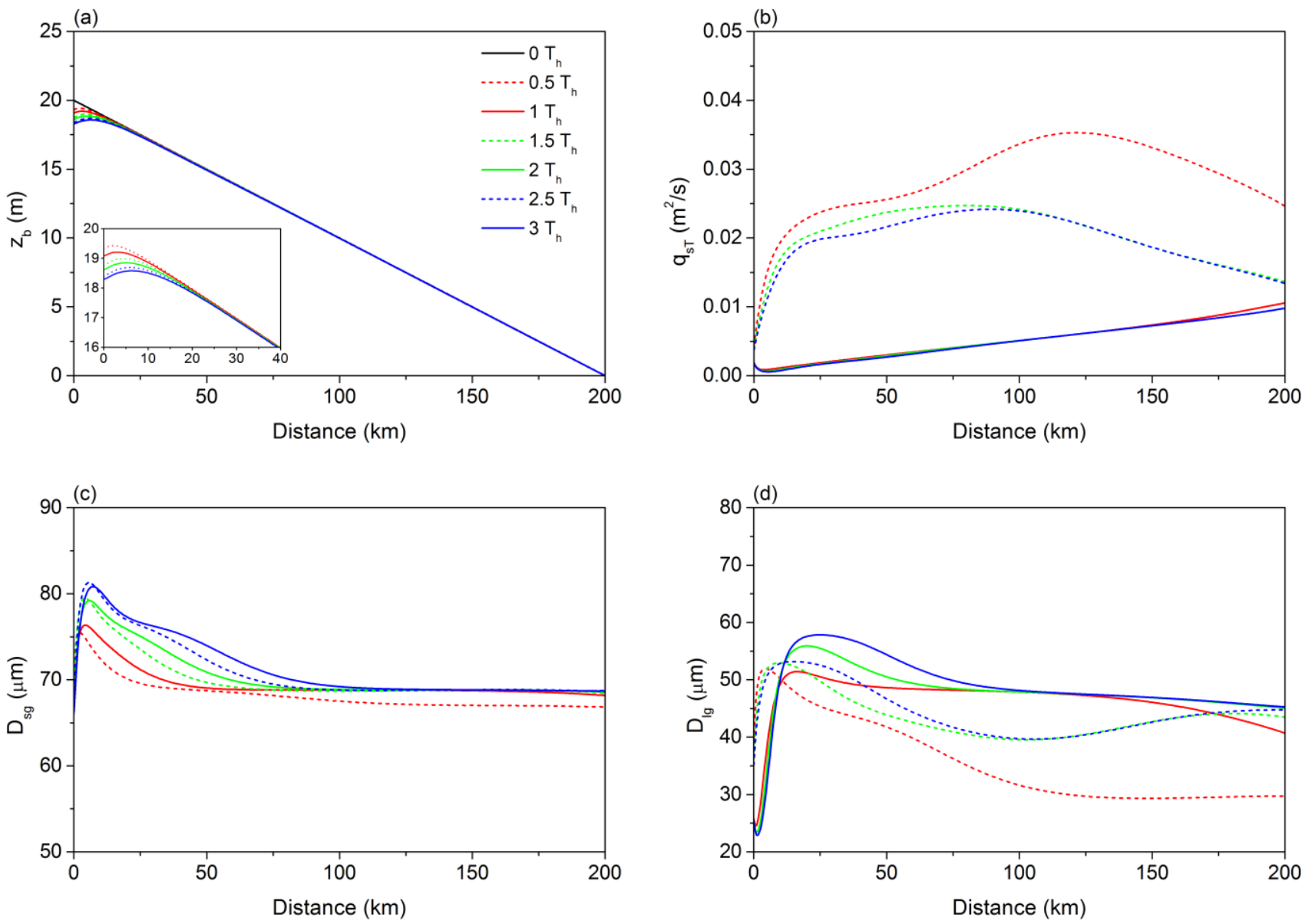

Figure S6. Results for sediment mixtures within 3 hydrographs simulated by the entrainment form of Exner equation: time variation of (a) bed elevation $z_{b}$, (b) total sediment load $q_{s T}$, (c) surface geometric mean grain size $D_{s g}$ and (d) geometric mean grain size of sediment load of the LYR in response to the cutoff of sediment supply. The inset shows detailed results near the upstream end. The dash lines are at the peak discharge and the solid lines are at the minimum discharge.

\section{S4: Iterative solution of sediment transport rate $q_{s i}$ in the entrainment form}

The parameter $q_{s i}$ in Eq. (40) of the main text is solved iteratively as given below, 
$76 \quad q_{s i}{ }^{(m+1)}=q_{s e i}-\frac{q_{w}}{v_{s i} r_{o i}}\left[\frac{1}{I_{f}} \frac{\partial\left(\frac{q_{s i}^{(m)}}{u}\right)}{\partial t}+\frac{\partial q_{s i}{ }^{(m)}}{\partial x}\right]$

77 where the superscript denotes the order of iteration. The following zero-order solution is specified as an initial value;

$78 \quad q_{s i}{ }^{(0)}=q_{\text {sei }}$

79 From this we can get the first order and second order solutions,

$q_{s i}^{(1)}=q_{s e i}-\frac{q_{w}}{v_{s i} r_{o i}}\left[\frac{1}{I_{f}} \frac{\partial\left(\frac{q_{s e i}}{u}\right)}{\partial t}+\frac{\partial q_{s e i}}{\partial x}\right]$

$q_{s i}^{(2)}=q_{s e i}-\frac{q_{w}}{v_{s i} r_{o i}} \frac{1}{I_{f}} \frac{\partial}{\partial t} \frac{1}{u}\left\{q_{s e i}-\frac{q_{w}}{v_{s i} r_{o i}}\left[\frac{1}{I_{f}} \frac{\partial\left(\frac{q_{s e i}}{u}\right)}{\partial t}+\frac{\partial q_{s e i}}{\partial x}\right]\right\}-\frac{q_{w}}{v_{s i} r_{o i}} \frac{\partial}{\partial x}\left\{q_{s e i}-\frac{q_{w}}{v_{s i} r_{o i}}\left[\frac{1}{I_{f}} \frac{\partial\left(\frac{q_{s e i}}{u}\right)}{\partial t}+\frac{\partial q_{s e i}}{\partial x}\right]\right\}$

The second order iterative solution to Eq. (S8) is tedious in form, but the only terms of importance on the right-hand

84 side are the spatial derivatives. Therefore we drop the time derivatives for simplicity. This gives,

$85 \quad q_{s i}=q_{s e i}-\frac{q_{w}}{v_{s i} r_{o i}} \frac{\partial}{\partial x}\left(q_{s e i}-\frac{q_{w}}{v_{s i} r_{o i}} \frac{\partial q_{s e i}}{\partial x}\right)$

86 which corresponds to Eq. (41) as implemented in Section 4.2 of the main text. 